November - 2004

\title{
Telling Story! Voice in Photography: An online visual art critical studies program evaluation
}

\author{
Sandra Semchuk \\ Emily Carr Institute \\ Canada \\ Laurel Tien \\ University of British Columbia \\ Canada
}

\begin{abstract}
This article highlights the current dialogue about educational technology and ways of knowing in visual art education. The authors outline and evaluate the development and testing phases of a hypertextual online visual art course offered at the then Emily Carr Institute of Art and Design (http://www.eciad.ca/www/) in the summer of 2001. Through this, we offer a framework for the evaluation of online visual art critical studies courses.
\end{abstract}

Keywords: online art education; digital technology; photography; hyper-textual online learning community; visual art

\section{Introduction}

Although many other areas of education have debated at length the impact of digital technology, art education is in the early stages of considering how the use of computer technology affects teaching and learning in the visual arts (for example, see Dunn, 1996; Gregory, 1996; Gregory,1997; Heise and Grandgennett, 1996; Julian, 1997; Krug, 1998; Prater, 2001; Taylor, 1999; Taylor and Carpenter, 2002; Taylor, 2004; Wongse-Sanit,1997). This paper focuses on the use of a specific hyper-textual online learning community at Emily Carr Institute (ECI), an educational institution specializing in the visual arts based in Vancouver, British Columbia, Canada. ECI is one of the first specialty educational institutions to experiment with hyper-textual online learning communities in North America. In this article, we report the design, implementation, and preliminary testing of the pilot of Telling Story: Voice in Photography, which took place in the summer of 2001. Through this, we offer a framework for the evaluation of online visual art learning communities and argue that, although the use of hypertext in online learning communities has the potential to facilitate new ways of knowing, more research needs to be done on the lived experience of participating in an online learning environment in visual art education. 


\section{Technology in Art Education}

The dialogue of the impact of computer technology on teaching and learning in visual art education is at an early stage. Two frameworks may be adopted to examine this debate; the purpose of the technology itself (Bruce, 1991; Dunn, 1996) and the dominant discourse (Boshier and Onn, 2000) of technology in art education.

Dunn (1996) proposes five purposes for technology in art education: 1) as an educational tool; 2) as a creative tool; 3) as a research tool; 4) as a curriculum development tool; and 5) as an assessment tool. To this list, can be added as a medium, and as a communication environment (Bruce, 1991). Of the articles we have found, about half discuss technology as a tool for creative projects (Dunn, 1996; Freedman, 1991; Gregory, 1996; Heise and Grandgennett, 1996; Marschalek, 2002; Taylor, 2000; Tomaskiewicz, 1997) and half discuss technology as a communication environment or medium for critical thinking (Gregory, 1996; Heise and Grandgennett, 1996; Prater, 2001; Stankiewicz and Garber, 2000; Taylor, 1999; Taylor and Carpenter, 2002). If visual art educators are to incorporate technology into active, constructivist curricula, technology will need to be not simply an add-on, but a communication medium that promotes critical thinking and the development of new knowledge or perspectives.

The second framework we will adopt to examine the discourse of technology in visual art education is that of Boshier and Onn (2000), who argue that the four discourses of technoutopianism, techno-cynicism, techno-zealotry, and techno-structuralism ("not interested in whether it is good, bad or neutral, but in the social context of where the Web is used") construct the realities of educational practice. In reviewing the literature on technology in art education, we have found that a majority of the articles are steeped in techo-utopianism (Carpenter, 2003; Dunn, 1996; Gregory, 1996; Heise and Grandgennett, 1996; Prater, 2001), blindly adding technology to curriculum. Boshier and Onn (2000) state that techno-utopianism dominates educational discourse by constructing Web learning and education as a paradigm shift, demeaning earlier forms of education/ distance education, and impeding the continuing dialogue of teaching and learning with computer technologies.

If technology in art education is to be dialogued in a balanced way, we argue that the dialogue must move past technology as tool into technology as communication medium, and from technoutopianism to techno-structuralism. Only at this point will visual art educators use digital interactive computer technology to construct new knowledge about art.

\section{Overview of the Course "Telling Story"}

This online course asks: How do we tell story in an age of information using photography?

Story can locate both teller and recipient in the transitional experience of coming to know. Where we come to know, how, when and with whom, are questions that lead towards the authorship of our own lives - those stories that constitute living immediate culture.

- This online studio based course (with a seminar component) will place the photographic stories of its participants in the center of the group's inquiry. Participants will develop their skills to make photographs, edit, sequence, and work with a range of non-linear narrative structures and forms including the use of text. 
- Relationships between oral, written, photographic and electronic media will be experienced and investigated. Participants are invited to use any format of photography that can be scanned and/ or digitized as originals or documentation. Both individual and collaborative projects are included.

- This course aims to create a learning community based on telling story through photographs that includes distance learners from diverse cultural, economic and geographic backgrounds. Designed to educate participants through visuals and design as well as through written stories and instruction, this course itself is an articulation of its own content.

- Students from ECI will meet with the instructor for an introduction to the course during week one. Distance participants are invited to join the class in Vancouver or will be supported by the instructor during the introductory section of the course.

- As this course is online in a largely asynchronous environment, where participants can schedule most of their own learning activities during each of the 14 week periods. Digitized photographs can be easily uploaded into the educational software used. Forums and chat spaces will be available for communication between participants and with the instructor.

- ECI computer resources are available for students registered in the institution. Participants can use their own computer resources at home as well. Both MAC and PC computers can be used. Participants using their home computers will need to have either Netscape or Explorer and Photoshop installed and a means of scanning or digitizing their photographs.

\section{Purpose and Scope of the Evaluation}

Overall, this study was motivated by two questions: What are the strengths and weaknesses of this medium for visual art critical studies courses? Are hyper-textual online learning communities a viable medium for visual art critical studies courses? Formative evaluation processes for Telling Story: Voice in Photography he course, with one participant dropping-out after only reading the course materials, and one participant engaging in the formulation of this paper. In this stage, the evaluation tool outlined in Appendix A was used and feedback was accepted through email submission.

It is important for the authors to acknowledge their biases in this paper; both authors are relatively new to the area of educational technology and do not consider themselves to be technology experts. Both authors are equally concerned with artistic practise and the education of art, wanting to evaluate this course in terms of the strengths and weaknesses of this medium for the field of art education, in order to stimulate dialogue such that current and future art educators can "walk into this area with eyes wide open."

\section{Brief Overview of the Design and Implementation of the Course}

Telling Story: Voice in Photography was developed by Sandra Semchuk as a three credit course to be delivered as part of the curriculum of the Department of Photography (four year BFA) and the School of Media Arts at ECI. This course was developed concurrently as a face-to-face (F2F) course as well as an online course, and is designed for third and fourth year learners who have a 
basic knowledge of Photoshop software, Web use, and have completed self-initiated projects in photography. Motivated by a desire to develop international learning communities using educational technology, Sandra has also found the experience has enriched her teaching practice and influenced her personal research in this area.

In terms of the design process, the course content was developed ahead of the infrastructure, starting in the Fall of 1999. Sandra states she found a lot of initial support in fellow faculty members, course designers, and available research. In the first year, most of the written text and half of the images were collected and compiled, constituting an "extraordinary amount of work." Similar to other educators new to educational technology (Harasim, Hiltz, Teles and Turoff, 1998), Sandra found the change in logistics from a more spontaneous to a linear and less intuitive progression to be challenging. Other initial challenges included copyrighting the visual materials and deciding on the form of the website. The focus of the course from the onset, was to a constructivist epistemology (Bednar, Cunningham, Duffy, and Perry, 1992), in which dialogue, critical thinking and the creation of a student learning community was central. To some extent, the model of one of the professors from the University of British Columbia School of Nursing was utilised (Green, 2001), as this model has been successful at incorporating group and collaborative work, as well as a framework proposed by Narthouse and Harthose (1985).

In the second year, the form was determined, after vacillations between different models and possible educational software. The issue was how to offer technical support with the resources available. Sandra developed and digitized the visual objects for the course often using her own photographs or making new images. Photographs from ECI's student community were solicited as examples, digitized, and educational copyright was sought. Support for the interface design. was given by the Director of ECI's Center for Art+Technology. A student from ECI was hired to assist with building the website, and Sandra speaks of this student's involvement as integral to the project; "It was an enormous project with over two thousand documents and minimal resources." Sandra states "the student who worked with me, Carollyne Ramsey, was also a teacher, so I saw her contributions as collaborative and consultative and well as being a learning experience for her." Using Dreamweaver software, the course website was built over the period of approximately 3.5 months (120 hrs student's time and 400 of Sandra's time). Sandra commented that if she was to do it again, that she would integrate the format and content from the beginning, rather than writing then designing. She also commented that the learning curves for her at each stage of the development of the project were steep, involved learning new technologies at each step, and a great deal Internet research and reading.

In terms of design of content and format, this ultimately asks the question: How do we tell story in the Age of Information using photography? Information from the course outline (ECI, 2001) expands on this:

Story can locate both teller and recipient in the transitional experience of coming to know. Where we come to know, how, when, and with whom are questions that lead towards the authorship of our own lives - those stories that constitute living immediate culture. This online studio-based course will place the photographic stories of its participants in the centre of the group's inquiry. Participants will develop their skills to make photographs, edit, sequence, and work with a range of non-linear narrative structures and forms including the use of text. Relationships between oral, written, photographic and electronic media will be experienced and investigated. Participants are invited to use any format of photography that can be scanned and/or digitized as originals or documentation. 
Both individual and collaborative projects are included (from "Telling Story" course outline, 2001).

The course objectives are seven-fold: 1) to be more aware of the narrative nature of experience, the value of photographs and story in creating and sustaining learning communities in a Web environment; 2) to be able to consider in their own photographic practise complex interplays between the oral, the written, and both analog and digital photography; 3) to be able to dialogue and collaborate using digitised photography within an online environment; 4) to be more aware of the adaptive strategies of contemporary storytelling using photography in an era of global communication; 5) to be able to develop narrative structures that disrupt conventional narrative and open up possibilities for audience participation; 6) to be critically more aware of social and cultural constructs that inhibit the communication of story; and 7) to be able to assess their own photography based on values that are integral to their own practise.

\section{Evaluation Methodology}

\section{Data Collection}

In the overall formative evaluation process, participants included 14 learners in the F2F version of the course, two active participants in testing classes one and two, one reader of classes one and two, four professionals in the field of photography, including two photographer/ professors, and participants from the Squamish Nation (see http://www.squamish.net/ for more information on the Squamish Nation).

\section{Evaluation during the Design Phase:}

Although this course was designed for online use, a part of the evaluative process was to see how effective these materials as learning objects could be used in an in-class situation. The in-class presentations also gave additional opportunities to access, by direct observation, the learners' response to the course materials. For example, where there seemed to be a lack of clarity, the course was modified accordingly. Sections of the online course were also tested by the F2F learners; class two was projected in the classroom as visual learning objects to support curriculum, and learners spent more in-depth time with the course materials in the computer lab.

The hereditary chief of the Squamish Nation, Chief Bill Williams, Chief Ian Campbell, Aaron Nelson-Moody, Nancy Bleck and other members of the Squamish Nation assessed the content and Design of Class 13 in which their nation is represented. Their significant suggestions deepened and expanded the content.

\section{Evaluation during the Testing Phase:}

The evaluation tool for the testing phase was developed by the authors with assistance from Carol Gigliotti's (ECI's Director of the Centre for Art+Technology) interface design criteria and is outlined in Appendix 1. It includes the categories of accessibility, art-making practice, and learning community/epistemology. 


\section{Data Analysis Process}

In the design phase, data analysis consisted of direct observation of learners in F2F version of class by instructor as well as discussions with experts from the Center for Art+Technology, from learners in the School of Media Arts at ECI, and from members of the photographic and digital community nationally and internationally. In the final testing phase, email transcripts and verbal comments were reviewed by both authors and themes determined.

\section{Results}

\section{From the Design Phase}

In the F2F version of the course, there was considerable excitement about the materials themselves, the visual ideas and the interface. It was clear, however, that the learners who where in the advanced stages of collaboration and group work, preferred the opportunity to have both their peers and their instructor in the flesh. It must be noted, however, that learners did not have an opportunity to engage one another in an online environment in that instance, so they were not able to experience the difference.

In terms of the sections of the online course tested in-class by the F2F learners, the two methods evoked different responses. The in-class method elicited more group interaction, whereas the computer lab method led to introspective responses where the dialogue with the material was internal. The transition from this introspective space to the group dynamics of the class was awkward. Perhaps a transition to small group dialogue with the materials would be more effective within the classroom situation.

\section{From Evaluation Tool}

\section{Accessibility}

Overall the feedback was positive in this area. Evaluators found there to be a good mixture of images and text; one evaluator commented on the website being "beautiful, rich, and complicated," while another commented on the "dense" nature. The non-linear nature of the website was commented on as being both an asset and a hindrance - an asset in the rich nature of the site and learning experience, but a hindrance to the desire to be able to print out the site's contents for ease of reading. The need for some experience with the Internet, and for time to 'play' with the website was acknowledged. One evaluator commented on the course being more demanding than he expected, a finding that is found in the literature (Harasim et al, 1998). Comments were also received on the few small technological glitches experienced, the sometimes lengthy download times for images and Quicktime movies, and the use of type colours to help facilitate reading. One participant commented on the positive nature of the asynchronous dialogue of the course: "I have time to ponder and formulate a response." An important consideration for the authors was the concept of 'transparency' of the medium; evaluators' comments indicated that transparency was a strength of the course design. Overall, the comments were very positive as to the aesthetic experience, the amount of exploration and dialogue encouraged, and the centrality of the participant to the learning experience. 


\section{Art Making Practice}

All evaluators found the course assisted with their own practice as photographers and storytellers; assisting to "revisit my own photographic practice," stimulate thoughts, and to bring a fresh perspective. One participant commented that she was: “. . . starting to fill her journal with ideas . . . having the asynchronous nature helped me to share ideas as I was ready.” Another evaluator found that current art-making projects had become more "alive" through the readings and discussions.

\section{Learning Community/ Epistemology}

Overall, the evaluators found the course design to be helpful in the area of creating a learning community through the use of dialogue and group learning activities. One evaluator commented on the "rush" of learning that occurred as other participant's contributions helped her to make new connections. Another commented on how they had "heavy thoughts regarding the course were with them all the time.” All commented on the non-hierarchical nature of the discussion forums, creating a "level-playing field" where opinions are sought, acknowledged and valued, and many points of view exist.

\section{Conclusions}

This paper has outlined the design, implementation, and preliminary testing of the pilot course entitled Telling Story: Voice in Photography. The answers to our initial questions - What are the strengths and weaknesses of this medium for visual art critical studies courses? Are hyper-textual online learning communities a viable medium for visual art critical studies courses? - have been explored through this descriptive formative evaluation process. As stated at the beginning of this paper, the evaluation process for this pilot course is ongoing.

Overall, the results of the evaluation process have been positive. The evaluation process appears to be influenced by a techno-utopian discourse, however. As such, further attempts to study this course need to be examined in more depth using multiple methodologies.

\section{Implications for Curriculum}

The results from this evaluation have implications for visual art curricula. First, educators need to be aware of the dialogue of techno-utopia. Technology can be a useful vehicle in helping students gain control over their own learning, but curriculum needs to be student-driven, not technologydriven. There can be a multitude of ways to incorporate technology, on all points of the spectrum, if we have the courage to look past the utopian discourse to make informed decisions about what technology can and cannot offer.

Second, tools for online learning need to become transparent, almost invisible means to learning rather than ends in themselves. Upcoming generations of students are urged to be increasingly techno-literate (Tapscott, 2004), and educators do need to consider how curricula will grow and adapt to meet the needs of this upcoming generation.

Third, if knowledge from each of the four areas of aesthetics, art criticism, art history, and art production are valued in visual art education (Darts, 2004; Duncum, 1999, 2001, 2002; Freedman, 1997, 2002, 2003; Garoian and Gaudelius, 2004; Stuhr, 2003; Tavin, 2000, 2002, 
2003), online curricula needs to be developed that reflect contents from each that facilitates the building of knowledge in a constructivist format. With the usual focus of online learning communities on the dialogic nature of learning, coupled with the challenging nature of hands-on skill development in virtual spaces, a balanced curriculum can be difficult to develop in online learning communities. De Cosson (2002) writes; "[visual] art learning is an embodied practice learned through praxis" (where praxis knowledge is the in-between theory and practice). If visual art learning is ultimately a bodily performance, is it possible to fully teach visual art courses through online learning communities? Is there space for embodied knowing?

\section{Summary}

Interactive computer technologies have the ability to provide the space, website and tools for encouraging students to engage in an active and growing learning environment. Through this change and growth can emerge a new way of knowing that becomes a part of those involved, which could engage them in further learning. Educators, however, need to tread into these waters carefully, being aware of the multiple ways that technology can be incorporated into art education, while avoiding the pitfalls of the language of techno-utopia. Although the use of hypertext in online learning communities has the potential to facilitate new ways of knowing, more research needs to be done on the lived experience of participating in an online learning environment in visual art education.

\section{References}

Bednar, A. K., Cunningham, D., Duffy, T. M., and Perry, J. D. (1992). Theory into Practice: How do we link. In T. M. Duffy and D. H. Jonassen (Eds.) Constructivism and the Technology of Instruction. Mahwah, NJ.: Lawrence Erlbaum.

Boshier, R., and Onn, C. M. (2000). Discursive Constructions of Web learning and Education. Journal of Distance Education 5(2). Retrieved July 2, 2004 from: http://cade.athabascau.ca/vol15.2/boshieretal.html

Bruce, B. (1991). Roles for computers in teaching the English language arts. In J. Flood, J. M. Jenson, D. Lapp, and J. R. Squire (Eds.) Handbook of research on teaching the English Language Arts (p. 536-541). New York: MacMillan.

Carpenter, B. S. (2003). Toward Non-Linear Curriculum Design: Hypertext and the preparation of teachers in art education. VCU Emerging Technologies Day. Retrieved July 18, 2004 from: www.at.vcu.edu/etech/etday/papers/carpenter.pdf

Darts, D. (2004). Visual Culture Jam: Art, pedagogy, and creative resistance. Studies in Art Education, 45(4), 313 - 327.

Duncum, P. (1999). A case for an art education of everyday aesthetic experiences. Studies in Art Education, 40(4), 295 - 311.

Duncum, P. (2001). Visual Culture: Developments, definitions, and directions for art education. Studies in Art Education, 42(2), 101 - 112. 
Duncum, P. (2002). Theorizing everyday aesthetic experience with contemporary visual culture. Visual Art Research, 28(2), 4 - 15.

Dunn, P. (1996). More Power: integrated interactive technology and art education. Art Education, 49(6), $6-11$.

Emily Carr Institute of Art and Design (2001). Course Outline for Telling Story. unpublished document.

Freedman, K. (1997). Teaching technology for meaning. Art Education, 50(3), 7 - 11.

Freedman, K. (2000). Social Perspectives on Art Education in the U.S.: Teaching visual culture in a democracy, Studies in Art Education, 41(4), 314 - 329.

Freedman, K. (2003). Teaching Visual Culture: Curriculum, aesthetics, and the social life of art. New York: Teachers College Press.

Garoian, C. R., and Gaudelius, Y. M. (2004). The Spectacle of Visual Culture. Studies in Art Education, 45(4), 298 - 312.

Green, C. (2001). Course Outline for NURS 312: Supportive Environments for the Health of Families. Distance Education and Technology, Continuing Studies, University of British Columbia.

Gregory, D. (1996). Art Education Reform: Technology as Saviour. Art Education, 49(6), 49 54.

Gregory, D. (1997). Art education reform and integrated art media. In New Technologies in art education (p. 131-145). Reston, VA.: National Office for Arts Accreditation in Higher Education.

Harasim, L., Hiltz, S., Teles, L., and Turoff, M. (1998). Learning Networks: A field guide to teaching and learning online. Cambridge, MA.: MIT Press.

Heise, D., and Grandgennett, N. (1996). Perspectives on the use of internet in art classrooms. Art Education, 49(6), 12 - 18.

Julian, J. (1997). In a Postmodern Backpack: Basics for the art teachers. Art Education, 50(3), 23 $-24,41-42$.

Krug, D. (1998). Electronic learning communities and art education. Arts and Learning Research: The Journal of the Arts and Learning SIG. American Education Research Association. University of Stout, WI.: Wisconsin Press.

Marschalek, D. (2002). Building Better Web-based Learning Environments: Thinking in 3's. Art Education, 55(4), 33 - 39.

Narthouse and Harthose (1985). Small Group Communication in Health Care Health Communication. New York: Prentice Hall. 
Prater, M. (2001). Constructivism and technology in art education. Art Education, 54(6), 43 - 48.

Stankiewicz, M., and Garber, E. (2000). Cyberfaculty: An experience in Distance Learning. Art Education, 53(1), 33 - 38.

Stuhr, P. (2003). A tale of why social and cultural content is often excluded from art education and why it should not be. Studies in Art Education, 44(4), 301 - 314.

Tavin, K. (2000). The impact of visual culture on art education. Journal of Multicultural and Cross-cultural Research in Art Education, 18(1), 37 - 40.

Tavin, K. (2002). Engaging Advertisements: Looking for meaning in and through art education. Visual Arts Researcher, 28(2), 38 - 47.

Tavin, K. (2003). Wrestling with Angels, Searching for Ghosts: Toward a critical pedagogy of visual culture. Studies in Art Education, 44(3), 197 - 213.

Taylor, P. G. (2000). Madonna and Hypertext: Liberatory learning in art education. Studies in Art Education, 41(4), 376 - 389.

Taylor, P. G., and Carpenter, B. S. (2002). Inventively Linking: Teaching and learning with computer hypertext. Art Education, 55(4), 6 - 12.

Taylor, P. G. (2004). Hyperaesthetics: Making sense of our technomediated world. Studies in Art Education, 45(4), 328 - 342.

Tomaskiewicz, F. (1997). A Ten-Year Perspective on Visual Art Technology. Art Education, 50(4), $13-16$.

Wongse-Sanit, N. (1997). Inquiry-based teaching using the world wide web. Art Education, 50(2), $19-24$.

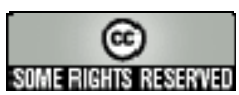

